\title{
Three-dimensional Discrete Element Simulation of Interaction between Aqueduct and Tunnel
}

\author{
Vahab Sarfarazi ${ }^{1 *}$, Hadi Haeri ${ }^{2}$, Kaveh Asgari ${ }^{3}$ \\ ${ }^{1}$ Department of Mining Engineering, Hamedan University of Technology, 6516913733 Hamedan, Iran \\ ${ }^{2}$ State Key Laboratory for Deep GeoMechanics and Underground Engineering, Beijing 100083, China \\ ${ }^{3}$ Research Scholar, Department of Mining Engineering, Shahid Bahonar University of Kerman, 7616913439 Kerman, Iran \\ * Corresponding author, e-mail: sarfarazi@hut.ac.ir
}

Received: 18 June 2021, Accepted: 18 August 2021, Published online: 10 September 2021

\begin{abstract}
In this investigation the effect of interaction between aqueduct and tunnel on the ground settlement has been examined using PFC3D. At first, the calibration of PFC3D was conducted based on UCS test results rendered from three different ground layer. Then intact model with dimension of $70 \mathrm{~m} \times 20 \mathrm{~m} \times 34.5 \mathrm{~m}(\mathrm{x} \times \mathrm{y} \times \mathrm{z})$ was built. These models are consisted of 8 layers with different mechanical and geometrical properties. Four different configurations for aqueduct were created in four models. Diameter of aqueduct was $2 \mathrm{~m}$ and its depth was different in four models. After aqueduct generation, tunnel with diameter of $9 \mathrm{~m}$ and length of $20 \mathrm{~m}$ was drilled in depth of $22 \mathrm{~m}$. After tunnel drilling, the settlement data of ground surface were picked up. After tunnel simulation, the effect of support lining was investigated on the ground settlement. For this purpose, after each step of tunnel drilling, lining support with diameter of $35 \mathrm{~cm}$ was performed. The results show that the maximum value of settlement occurred when aqueduct reach to head of tunnel. Also the safety has maximum value when the distance between aqueduct and tunnel wall was $4.5 \mathrm{~m}$. the ground settlement before and after support lining shows that ground settlement reach to zero by support application.
\end{abstract}

Keywords

tunnel, settlement, aqueduct, PFC3D

\section{Introduction}

Process of tunneling can induce surface settlements. This phenomenon is a complex process and many factors such as construction techniques, dimensions of tunnels and circumstances of soil and ground water affect this phenomenon [1]. Several new tunneling investigations has been applied for better prediction of soils respond to varieties of stress caused by construction of tunnel for providing accurate solutions for these problems [2-4]. Thus, there is still big preference for using empirical approaches in construction for initial prediction of settlement profile, this due to their simple use [5, 6]. Quick progress of computers, finite element (FE) and finite difference (FD) leads to more popularity of discrete element method (DEM) for prediction of soil respond to tunneling. Validation of these models was examined by comparing them with empirical and semi-empirical approaches, as well as, field observations. It is announced that empirical and semi-empirical approaches are still appropriate in specific circumstances and can be applied as a suitable method for validation of numerical models [7, 8]. In general, these empirical approaches for predicting surface settlements are according to a Gaussian distribution curve, first introduced by [9].

In these approaches all factors which affect both the predicted maximum and lateral settlements, must be inputted. Despite simplicity and successful appliance of empirical methods in prediction of surface settlement with suitable judgment, there are several limitations. These limitations include applicably to various tunnel geometries, ground circumstances and techniques of construction [10]. The Gaussian equation is the most common empirical approach which was popularized by investigation of Peck [11] and Schmidt [12] showing that it provides a representation of observed settlements with appropriate accuracy. One of the models using for testing its adequacy was Centrifuge modelling, with results from [13] and [14] reporting settlement profiles of the shape suggested by a Gaussian equation. Another method which has been widely used as a comparison with this equation, is field measurements. 
For instance, investigation by [15] includes such comparisons. New and O'Reilly [16] reviewed the ground movements associated with tunneling and found that the main dangers associated with the tunnel construction in urban areas with problems such as poor ground circumstances, presence of water table above the tunnel, shallow overburden and ground settlements induced by tunneling with potential damage to the existing structures and utilities on top of tunneling area. Mair and Taylor [17] studied the components of ground deformation associated with closed shield tunneling. The use of EPB machines with full tunnel face support significantly reduce the total volume loss as the tunnel advances. Clough and Schmidt [18] observed that the ground loss of the tunnel face contributed $1 / 4$ to $1 / 3$ to the total volume loss. The effects of interaction in between the twin tunnels on the ground subsidence, subsurface movements and spread of stress and displacement in the surrounding rock mass and the tunnel support are all being investigated experimentally and numerically by several researchers in this field of engineering [19-42]. The discrete element method can be effectively used for the stability analyses of the underground structures. Therefore, in this paper, the interaction between tunnel subway and aqueduct at Qom Province in Iran has been investigation using a three dimensional discrete element code i.e. PFC3D. In fact, the settlement of ground surface has been determined during the sequence stages of drilling, and the effect of lining has been cleared on the tunnel stability.

\section{Bonded particle model and Particle Flow Code 3D (PFC3D)}

A three-dimensional discrete element code originally developed by Cundall [43] is used to simulate a twin tunnels problem in this research. This sophisticated numerical code is the particle flow code (PFC3D) presented by Itasca [44]. In this modeling approach, the materials are assumed to be as an assembly of particles bonded to one another at the contact points but each particle can move independently within the assembly (Itasca [44]). In this code, the interaction contact forces and the movements of particles within a particular particle assembly are being estimated by using an explicit finite difference method of numerical analyses. In this numerical simulation process, the linear and non-linear contact models are adopted by taking into account the frictional sliding of the particles at the contact points or particle boundaries. The linear contact modeling approach is used to model the elastic behavior of the particles contact points within the assembly (i.e., to model the relative movements and the contact forces in between the particles). The PFC3D presented by Itasca [44], provided some special subroutines to generate a parallel bond particle model for solving many complicated geomechanical problems occur in various rock mass situations. The following micromechanical properties are being used by this modeling Algorithm in PFC3D: the stiffness ratios (i.e., $K_{n}$ over $K_{s}$ ), the ball-to-ball contact modulus, the frictional coefficients of the balls, the balls radius, the normal and shear bonding strengths of the parallel bonds, the parallel-bonds radius multiplier, the stiffness ratio and modulus of the parallel-bonds. A suitable calibration process is used in this modelling technique to establish appropriate micro-mechanical properties based on the laboratory measured properties provided by the standard testing procedures carried out on the actual material specimens. The actual material properties gained experimentally from the laboratory tests are the macro properties due to the continuum behavior assumption imposed on the specimens. However an inverse modeling technique based on the trial and error approach is adopted in PFC3D (Itasca [44]). However, this algorithm provides the appropriate micro mechanical properties for the particles in the assembly from the macro mechanical properties gained in the Laboratory by the experimental tests. This simulation procedure is needed for the solution of any geomechanical problems to be solved numerically by the explicit discrete element method. Therefore, the micro mechanical properties are assumed first and the problem is solved for the estimation of the strength and deformation characteristics near to those of macroscopic laboratory results. This is a repetitive procedure to reach to the micromechanical properties giving simulated macroscopic properties very close to those of experimentally obtained values from the laboratory tests. Then, these microscopic properties can be adopted for the numerical simulation of the discontinuous particles or blocks of the simulated material.

\section{Subway tunnel in Qom province}

Line A of subway tunnel in Qom Province has 14 stations with the length of $14700 \mathrm{~m}$. tunnel diameter was 9 $\mathrm{m}$ and its depth was $22 \mathrm{~m}$. The excavation method was EPB. Several aqueducts exist in excavation path (Fig. 1). In Fig. 1, dotted line shows the tunnel excavation path and the red line shows the aqueduct. The tunnel interact with aqueduct when tunneling progress was 5-6 km (Fig. 1). 


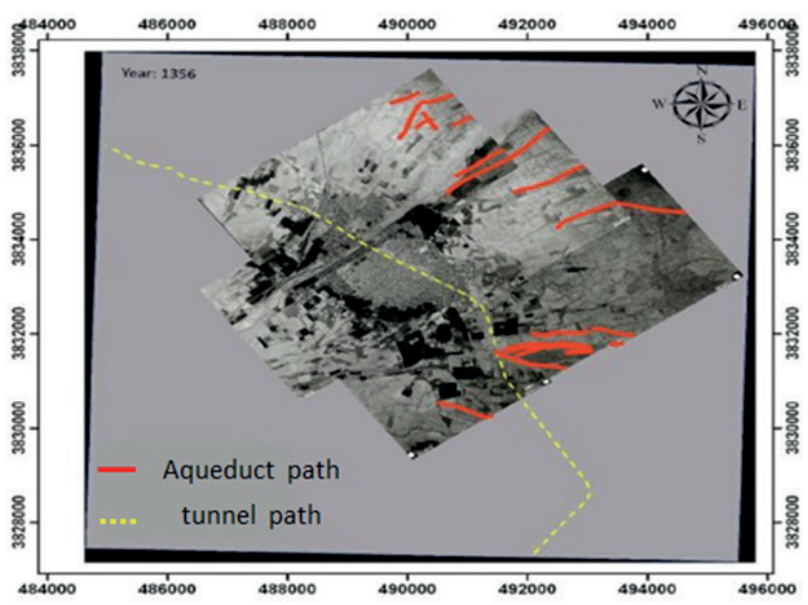

Fig. 1 Tunnel path and aqueduct

\section{Calibration of PFC3D}

The calibration of the PFC3D was accomplished by calibrating the mechanical properties of the specimen obtained from the rectangular models. Four steps were involved to generate a PFC3D material assembly to represent the uniaxial rectangular model: i) generating and packing of the particles; ii) installing the isotropic stress condition, iii) eliminating the floating particles; and iv) installing the particles bonding. The standard calibration process proposed by Cundall [43] and the micro-properties listed in Table 1 are adopted to calibrate the PFC3D calibration of
Table 1 Microparameter for model calibration

\begin{tabular}{lccc}
\hline & $k_{n}(\mathrm{~N} / \mathrm{m})$ & $k_{s}(\mathrm{~N} / \mathrm{m})$ & $\begin{array}{c}\text { Range of Ball } \\
\text { diameter }(\mathrm{m})\end{array}$ \\
\hline Layer 1 & $3 \mathrm{e} 7$ & $3 \mathrm{e} 7$ & $0.01-0.16$ \\
Layer 2 & $0.6 \mathrm{e} 7$ & $0.6 \mathrm{e} 7$ & $0.01-0.15$ \\
Layer 3 & $0.8 \mathrm{e} 7$ & $0.8 \mathrm{e} 7$ & $0.01-0.07$ \\
& $n$-bond $(\mathrm{N} / \mathrm{m})$ & $s$-bond $(\mathrm{N} / \mathrm{m})$ & $\rho\left(\mathrm{kg} / \mathrm{m}^{3}\right)$ \\
Layer 1 & $1 \mathrm{e} 6$ & $1 \mathrm{e} 6$ & 2400 \\
Layer 2 & $0.15 \mathrm{e} 6$ & $0.15 \mathrm{e} 6$ & 2300 \\
Layer 3 & $0.45 \mathrm{e} 6$ & $0.45 \mathrm{e} 6$ & 2200 \\
\hline
\end{tabular}

the particle assembly of the uniaxial model for three different types of soil layers. It's to be note that if the particle diameter be more than $160 \mathrm{~mm}$, the number of total balls will be decreased and high settlement will be occurred during the tunneling. If the particle diameter be less than $100 \mathrm{~mm}$, the number of total balls will be increased. This leads to increasing the run time of the model simulation. Also, the robust system will be necessary for this important. The porosity of model was 0.08 . This value is based on the PFC manual and leads to better distribution of particles in the domain of model.

Fig. 2 also illustrates the stress-strain curve of models. Table 2 shows mechanical properties of experimental test and numerical simulation. A good accordance was

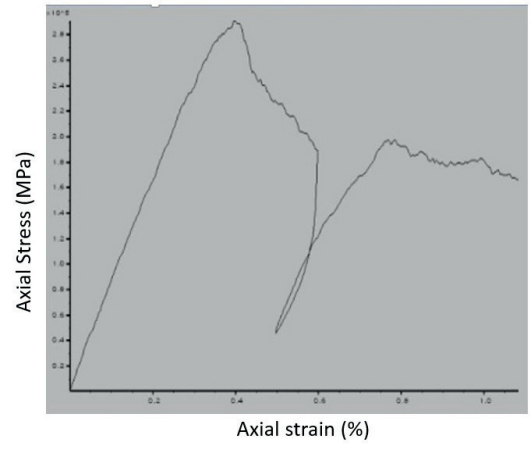

(a)

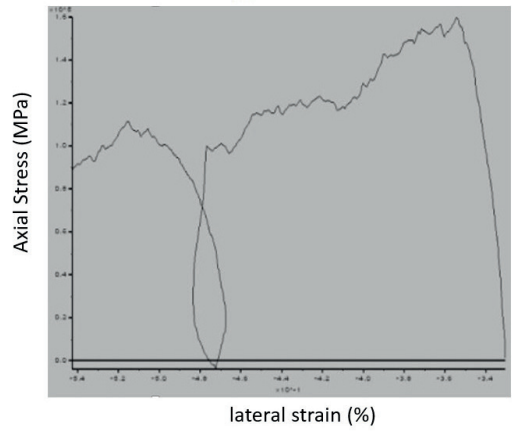

(d)

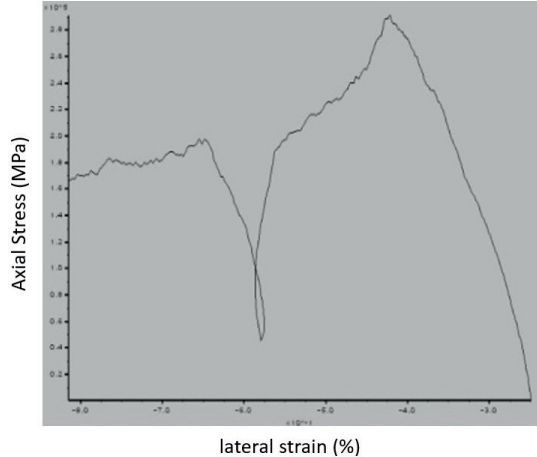

(b)

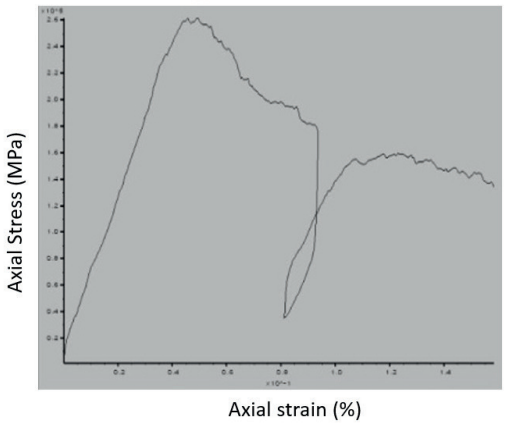

(e)

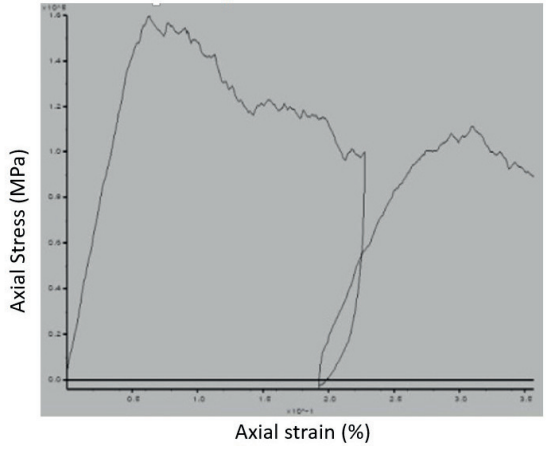

(c)

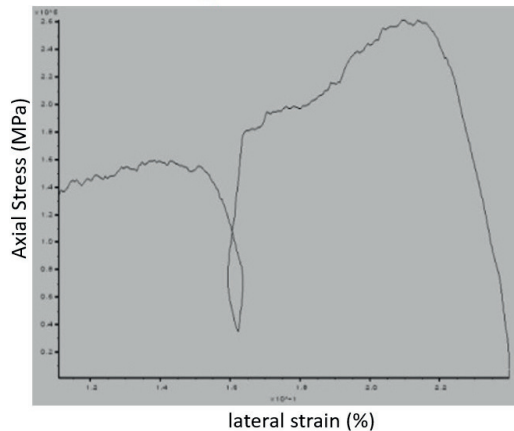

(f)

Fig. 2 a, c and e) axial stress versus axial strain; b, d and f) axial stress versus lateral strain 
Table 2 mechanical property of experimental test and numerical simulation

\begin{tabular}{lccc}
\hline $\begin{array}{l}\text { Type of } \\
\text { simulation }\end{array}$ & \multicolumn{3}{c}{ Experimental results } \\
\hline $\begin{array}{l}\text { Mechanical } \\
\text { properties }\end{array}$ & $\begin{array}{c}\text { Uniaxial strength } \\
(\mathrm{MPa})\end{array}$ & $\begin{array}{c}\text { Young } \\
\text { modulus }(\mathrm{GPa})\end{array}$ & Poisson ratio \\
First model & 0.3 & 1.07 & 0.49 \\
Second model & 0.15 & 3.28 & 0.44 \\
Third model & 0.35 & 5.817 & 0.48 \\
$\begin{array}{l}\text { Type of } \\
\text { simulation }\end{array}$ & \multicolumn{4}{c}{ Numerical simulation out puts } \\
\hline Mechanical & Uniaxial strength & Young & Poisson ratio \\
properties & $(\mathrm{MPa})$ & modulus (GPa) & \\
First model & 0.29 & 1.03 & 0.29 \\
Second model & 0.16 & 3.2 & 0.42 \\
Third model & 0.26 & 5.9 & 0.45 \\
\hline
\end{tabular}

established between experimental test results and numerical simulation outputs. These mechanical results demonstrating a good agreement and well matching in between the numerical and experimental results and validate the calibration procedure of PFC3D.

\subsection{Model calibration using 3-axial compression test in PFC3D}

Three different model representatives of three different geological layers have been built. Dimensions of rectangular models were $10 \mathrm{~m} \times 5 \mathrm{~m} \times 5 \mathrm{~m}$ (Fig. 3 ). These models are under six confining pressure. i.e., $\sigma c / 2$ to $\sigma c / 10$. Fig. 4 shows principal stress diagram for these layers.

Table 3 shows shear properties of experimental out puts and numerical simulation results.

A good accordance was established between experimental test results and numerical simulation outputs.

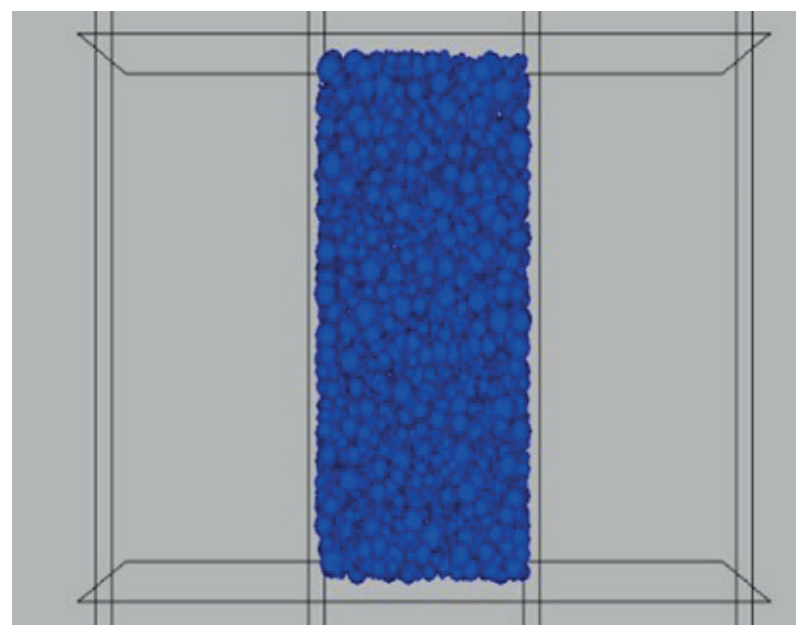

Fig. 3 Triaxial model in PFC3D

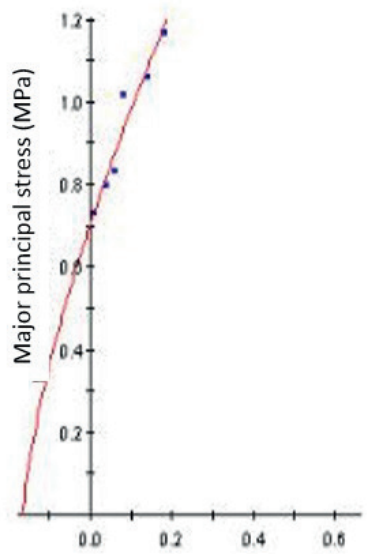

(a)

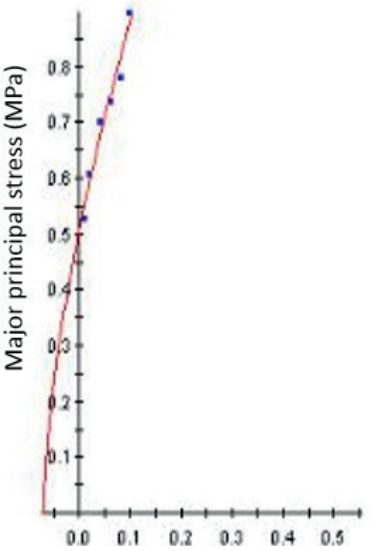

(b)

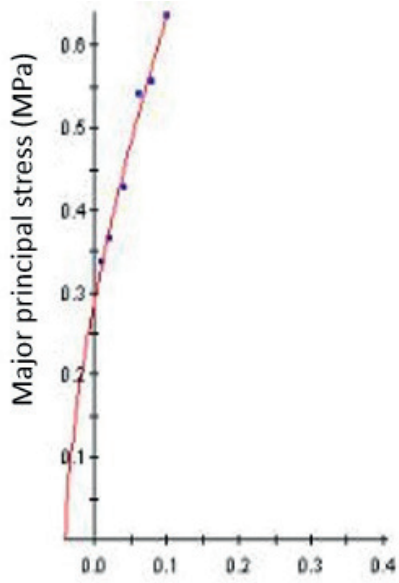

(c)

Fig. 4 principal stress diagram for three models, a) first model, b) second model, c) third model

Table 3 shear properties of three calibrated models

\begin{tabular}{lcc}
\hline Type of simulation & \multicolumn{2}{c}{ Experimental results } \\
\hline $\begin{array}{l}\text { Mechanical } \\
\text { properties }\end{array}$ & Cohesion (MPa) & Friction angle \\
First model & 0.02 & 24.2 \\
Second model & 0.007 & 14.5 \\
Third model & 0.026 & 22.3 \\
Type of simulation & Numerical simulation out puts \\
Mechanical & Cohesion (MPa) & Friction angle \\
properties & & 31.35 \\
First model & 0.02 & 16.43 \\
Second model & 0.007 & 25.86 \\
Third model & 0.024 & \\
\hline
\end{tabular}

\subsection{Model preparation}

The model with dimension of $70 \mathrm{~m} \times 20 \mathrm{~m} \times 34.5 \mathrm{~m}$ was built (Fig. 5). This model has been occupied with 50176 balls. This assembly was subjected to $2 \mathrm{MPa}$ of confining pressure. The unbalance force and displacement vector was set to zero before tunnel generation. 


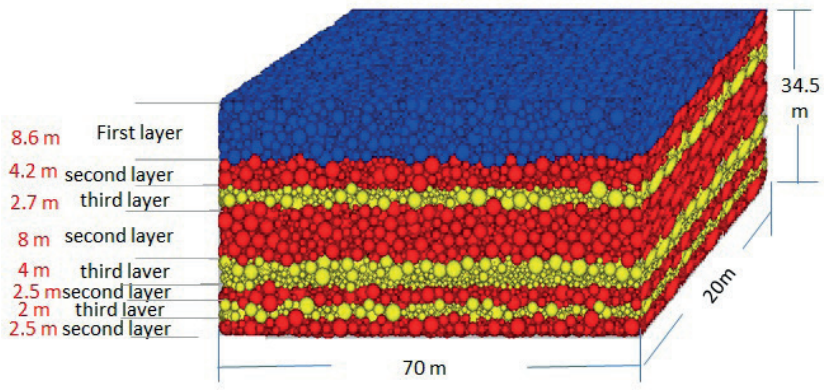

Fig. 5 Model assembly with three different soil layers

Whereas the aim of this paper is interaction between aqueduct and tunnel, four different configurations for pair of aqueduct were prepared as follow:

a) First model: aqueducts intersect the tunnel subway In this configuration tunnel was situated at the depth of $22 \mathrm{~m}$ and two aqueduct intersect the tunnel head (Fig. 6(a)). The distance between two aqueducts was equal to $6 \mathrm{~m}$. Diameter of two aqueducts was $2 \mathrm{~m}$.

b) Second model: aqueducts intersect the right side of tunnel subway

In this configuration tunnel was situated at the depth of $22 \mathrm{~m}$ and two aqueduct intersect the right side of the tunnel head (Fig. 6(b)). The distance between two aqueducts was equal to $6 \mathrm{~m}$. diameter of two aqueducts was $2 \mathrm{~m}$.

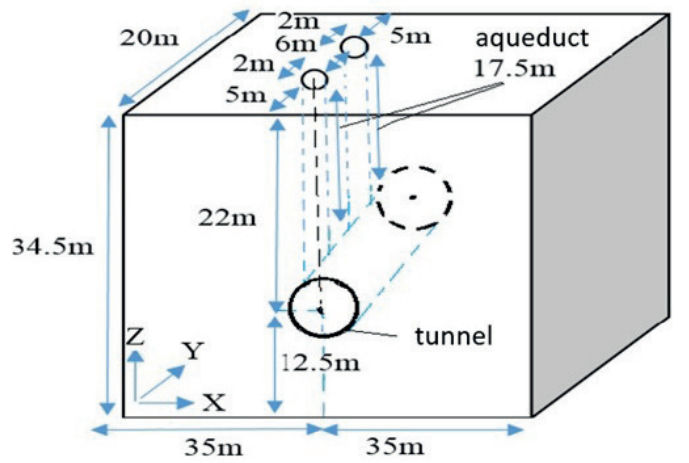

(a)

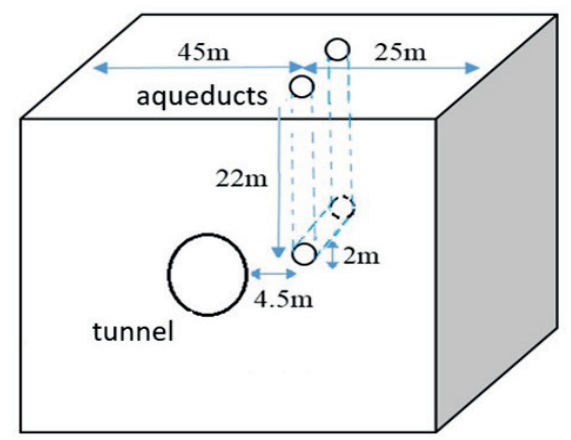

(c) c) Third model: aqueducts exist at a distance of $4.5 \mathrm{~m}$ from right side of tunnel subway

in this condition, aqueducts exist at a distance of $4.5 \mathrm{~m}$ from right side of tunnel subway (Fig. 6(c)). Aqueducts depth was $22 \mathrm{~m}$. One horizontal hole intersects the aqueduct. Diameter of hole was $2 \mathrm{~m}$.

d) Fourth model: aqueducts exist above the tunnel head In this condition, aqueducts exist above the tunnel head (Fig. 6(d)). Aqueducts depth was $10 \mathrm{~m}$. One horizontal hole intersects the aqueduct. Diameter of hole was $2 \mathrm{~m}$.

\subsection{Tunnel drilling during several steps in PFC3D}

After generating the aqueduct, tunneling with diameter of $9 \mathrm{~m}$ at depth of 22 were performed in 10 steps with $2 \mathrm{~m}$ progress in each step. Firstly one tunnel with diameter of $4.5 \mathrm{~m}$ was drilled in the center of the principal tunnel then principal tunnel with diameter of $9 \mathrm{~m}$ was created. This leads to decreasing the unbalance force in the model. Fig. 7 shows the schematic view of drilling stages and aqueduct configuration related to first condition. Fig. 8 shows the first model simulated in PFC3D. After creation of aqueduct condition, the first stage of tunnel drilling with length of $2 \mathrm{~m}$ was performed and then model start to balance. The settlement of 15 balls in ground surface and above the drilling face was selected and averaged as a ground settlement.

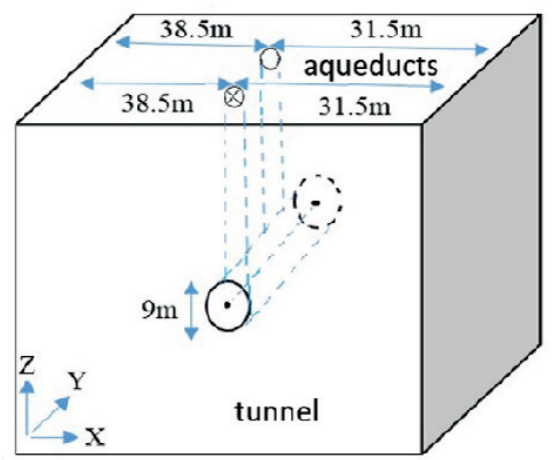

(b)

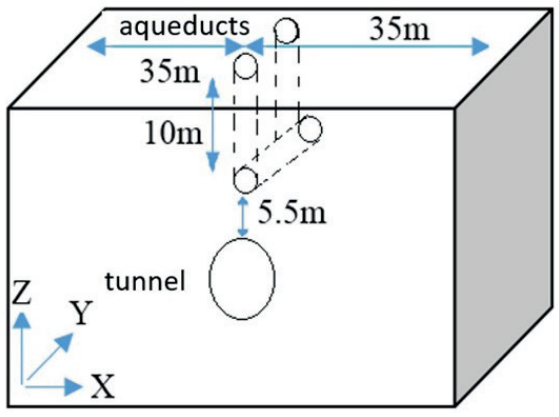

(d)

Fig. 6 a) aqueducts intersect the right side of tunnel subway, b) Two aqueduct intersect the tunnel head, c) aqueducts exist at a distance of 4.5 m from right side of tunnel subway, d) aqueducts exist above the tunnel head 


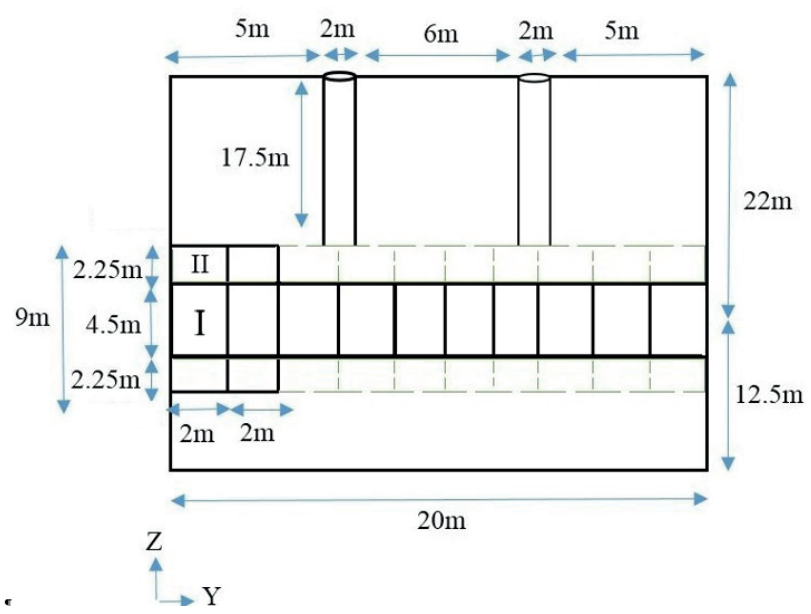

Fig. 7 the schematic view of drilling stages and aqueduct configuration related to first condition

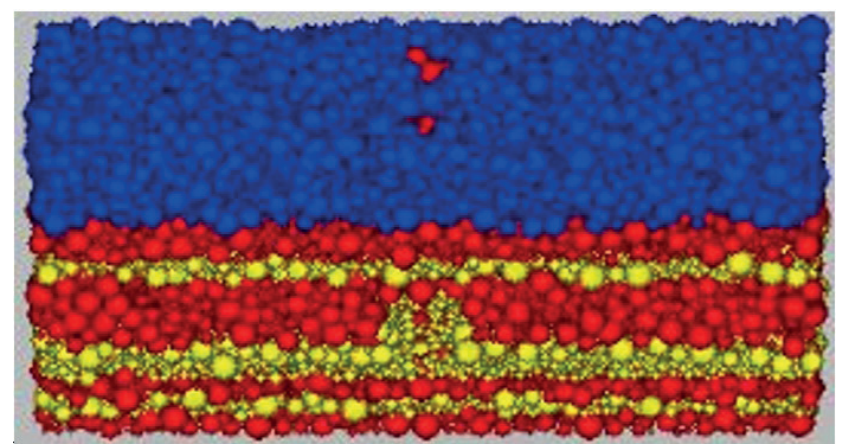

Fig. 8 the first model simulated in PFC3D

\subsection{Lining support in numerical simulation}

After tunneling in four model and registration of settlement data, the effect of lining support on the ground control was investigated. For this purpose, the lining support applied in place after drilling of each stage (Fig. 9).

The thickness of concrete lining was $35 \mathrm{~cm}$. Table 4 shows the micro parameters of concrete lining.

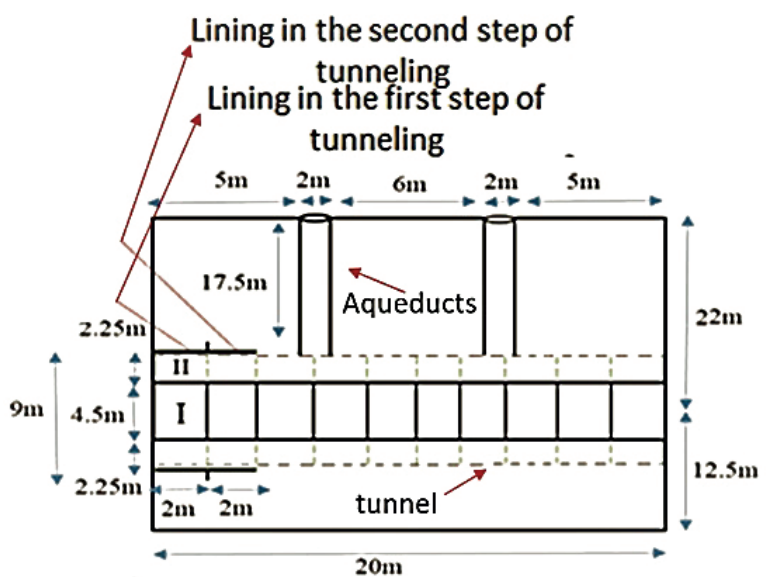

Fig. 9 Application of lining support in place after drilling of each stage
Table 4 The micro parameters of concrete lining

\begin{tabular}{cccccc}
\hline $\begin{array}{c}k_{n} \\
(\mathrm{~N} / \mathrm{m})\end{array}$ & $\begin{array}{c}k_{s} \\
(\mathrm{~N} / \mathrm{m})\end{array}$ & $\begin{array}{c}n \text {-bond } \\
(\mathrm{N} / \mathrm{m})\end{array}$ & $\begin{array}{c}s \text {-bond } \\
(\mathrm{N} / \mathrm{m})\end{array}$ & friction & $\begin{array}{c}\rho \\
\left(\mathrm{kg} / \mathrm{m}^{3}\right)\end{array}$ \\
\hline $2 \mathrm{e} 10$ & $2 \mathrm{e} 10$ & $1 \mathrm{e} 15$ & $1 \mathrm{e} 15$ & 0.1 & 2400 \\
\hline
\end{tabular}

5 The settlement before performing the support lining 5.1 The effect of drilling on the ground settlement for different configurations of aqueducts

Fig. 10 shows the ground settlement profile during 10 stages of drilling related to first model.

In total, the settlement is maximum above the tunnel face. The settlement is decreased by increasing the distance from tunnel axis. In the first model, in drilling stages of 6 and 14 the settlement has maximum value, i.e., $32 \mathrm{~mm}$ and $36 \mathrm{~mm}$ respectively, because tunnel intersects with aqueduct. The settlement was decreased by increasing the distance from aqueduct.

Fig. 11 shows the longitudinal profile of settlement in the first model. In drilling stages of 6 and 14 the settlement has maximum value, i.e. $32 \mathrm{~mm}$ and $36 \mathrm{~mm}$ respectively, because tunnel intersects with aqueduct. The settlement was decreased by increasing the distance from aqueduct.

Fig. 12 shows the ground settlement profile during 10 stages of drilling related to second model.

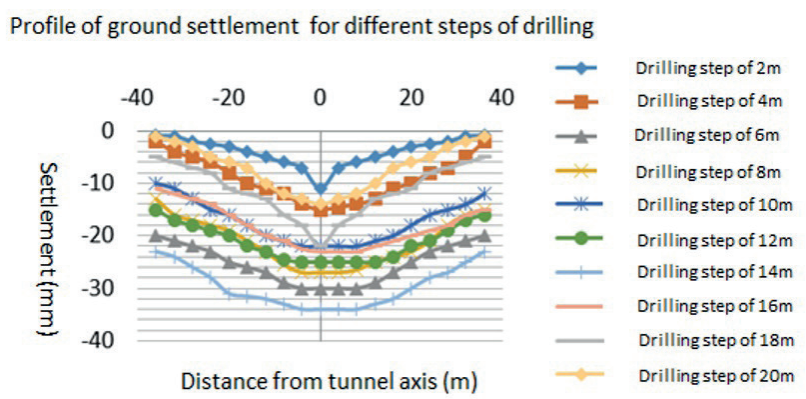

Fig. 10 the ground settlement profile during 10 stages of drilling related to first model

Longitudinal profile of settlement in the first model

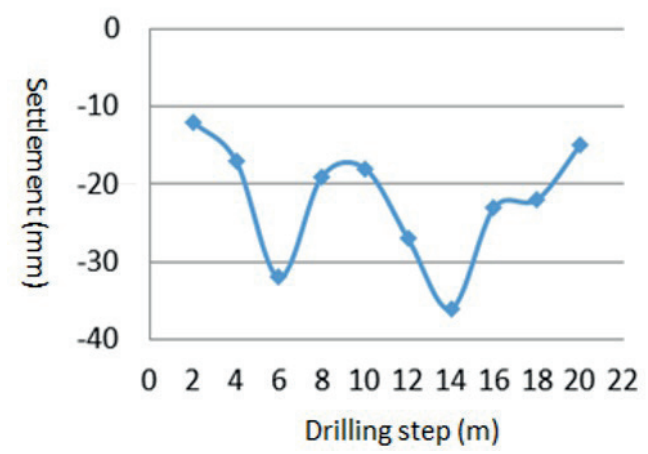

Fig. 11 the longitudinal profile of settlement in the first model 
Profile of ground settlement for different steps of drilling

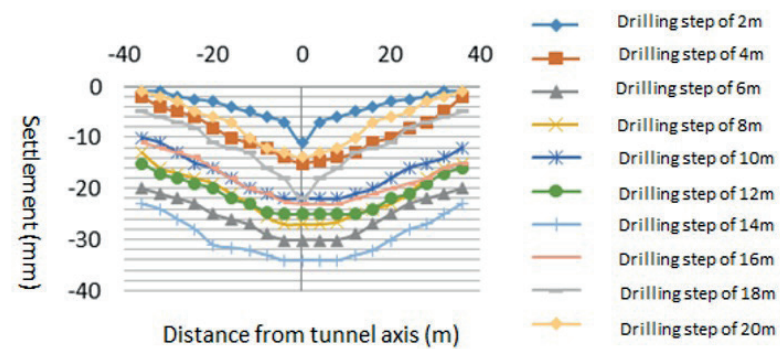

Fig. 12 the ground settlement profile during 10 stages of drilling related to second model

In the first stage of drilling, the ground settlement curve was aximetric because the aqueduct has not any effect of the ground settlement. In this condition, only tunneling lead to ground settlement.

During the secound stage of drilling to seventh stages of drilling, the ground settlement curve was un-aximetric because the aqueduct has important effect on the ground settlement. In this condition, tunneling lead to ground settlement too.

In drilling stages of 6 and 14 the settlement was maximum, i.e., $32 \mathrm{~mm}$ and $36 \mathrm{~mm}$ respectively, because tunnel intersects with aqueduct. The settlement was decreased by increasing the distance from aqueduct.

During the seventh stages of drilling to tenth stages of drilling, the ground settlement curve was aximetric because the aqueduct has not any effect on the ground settlement. In this condition, only tunneling leads to ground settlement.

Fig. 13 shows the longitudinal profile of settlement in the first model. In drilling stages of 6 and 14 the settlement was maximum, i.e., $32 \mathrm{~mm}$ and $36 \mathrm{~mm}$ respectively, because tunnel intersects with aqueduct. The settlement was decreased by increasing the distance from aqueduct.

Fig. 14 shows the ground settlement profile during 10 stages of drilling related to third model. In the first stage of drilling, the ground settlement curve was aximetric because the aqueduct has not any effect of the ground settlement. In this condition, only tunneling lead to ground settlement.

During the second stage of drilling till seventh stages of drilling, the ground settlement curve was un-aximetric because the aqueduct has important effect on the ground settlement. In this condition, tunneling lead to ground settlement too.

In drilling stages of 6 and 14 the settlement has maximum value, i.e., $32 \mathrm{~mm}$ and $36 \mathrm{~mm}$ respectively, because tunnel intersects with aqueduct. The settlement was decreased by increasing the distance from aqueduct.
During the seventh stages of drilling to tenth stages of drilling, the ground settlement curve was aximetric because the aqueduct has not any effect on the ground settlement. In this condition, only tunneling leads to ground settlement.

Fig. 15 shows the longitudinal profile of settlement in the secound model. In drilling stages of 6 and 14 the settlement was maximum, i.e., $32 \mathrm{~mm}$ and $36 \mathrm{~mm}$ respectively, because tunnel intersects with aqueduct. The settlement was decreased by increasing the distance from aqueduct.

Fig. 16 shows the ground settlement profile during 10 stages of drilling related to forth model.

In the first stage of drilling, the ground settlement curve was aximetric because the aqueduct has not any effect of the ground settlement. In this condition, only tunneling lead to ground settlement.

Longitudinal profile of settlement in the first model

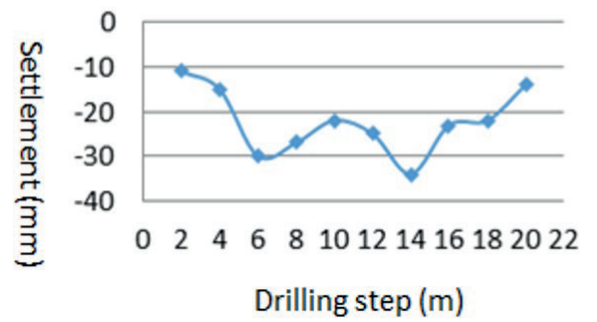

Fig. 13 the longitudinal profile of settlement in the second model

Profile of ground settlement for different steps of drilling

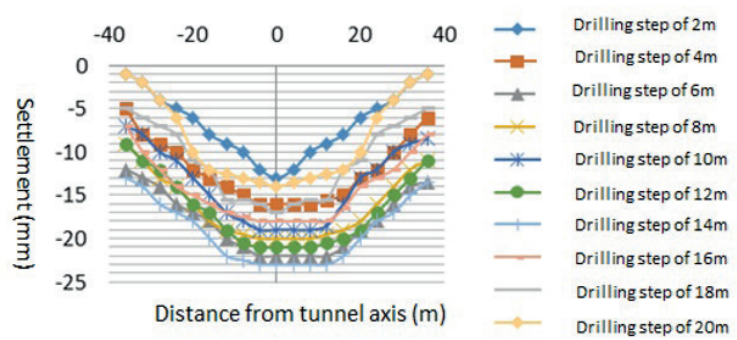

Fig. 14 the ground settlement profile during 10 stages of drilling related to third model

Longitudinal profile of settlement in the first model

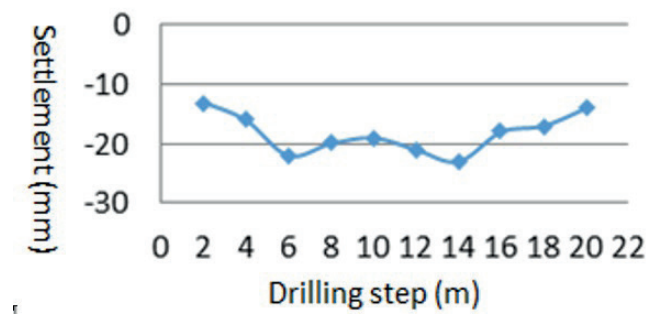

Fig. 15 the longitudinal profile of settlement in the third model 
Profile of ground settlement for different steps of drilling

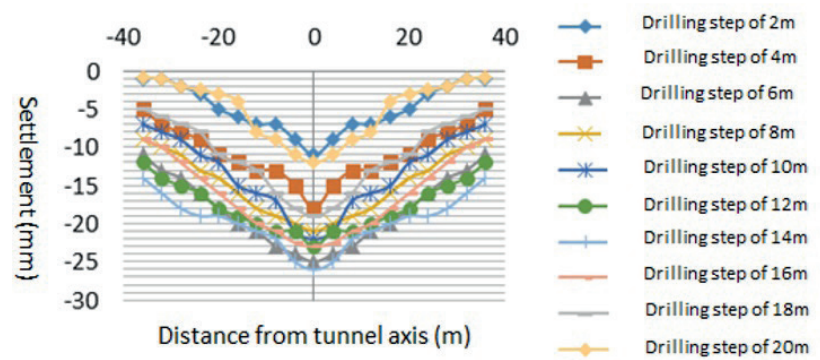

Fig. 16 the ground settlement profile during 10 stages of drilling related to forth model

During the second stage of drilling to seventh stages of drilling, the ground settlement curve was un-aximetric because the aqueduct has important effect on the ground settlement. In this condition, tunneling lead to ground settlement too.

In drilling stages of 6 and 14 the settlement has maximum value, i.e. $32 \mathrm{~mm}$ and $36 \mathrm{~mm}$ respectively, because tunnel intersects with aqueduct. The settlement was decreased by increasing the distance from aqueduct.

During the seventh stages of drilling to tenth stages of drilling, the ground settlement curve was aximetric because the aqueduct has not any effect on the ground settlement. In this condition, only tunneling leads to ground settlement.

Fig. 17 shows the longitudinal profile of settlement in the second model. In drilling stages of 6 and 14, the settlement has maximum value, i.e., $32 \mathrm{~mm}$ and $36 \mathrm{~mm}$ respectively because the tunnel intersects with aqueducts. The settlement was decreased by increasing the distance from aqueducts.

\section{The ground settlement after support lining}

Fig. 18 shows diagram of settlement before and after the support lining for the first model. Diagram of settlement before support lining has been shown in drilling stages of 6 and 14 that settlement has maximum value. The settlement was zero when the lining support was installed.

Longitudinal profile of settlement in the first model

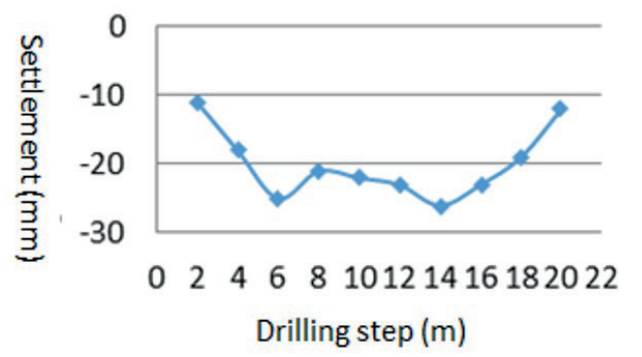

Fig. 17 the longitudinal profile of settlement in the fourth model
This behavior was similar in various sequence of tunneling for different configuration of aqueduct. Whereas this behavior was general in tunnel engineering, we didn't discuss any more.

\section{Conclusions}

In this investigation the influence of interaction between aqueduct and tunnel on the ground settlement has been investigated using PFC3D. At first, calibration of PFC3D was performed based on UCS test results rendered from three different ground layer. Then intact model with dimension of $70 \mathrm{~m} \times 20 \mathrm{~m} \times 34.5 \mathrm{~m}(\mathrm{x} \times \mathrm{y} \times \mathrm{z})$ was built. These models are consisted of 8 layers with different mechanical and geometrical properties. Four different configurations for aqueduct were created in four models. Diameter of aqueduct was $2 \mathrm{~m}$ and its depth was different in four models. After aqueduct generation, tunnel with diameter of $9 \mathrm{~m}$ and length of $20 \mathrm{~m}$ was drilled in depth of $22 \mathrm{~m}$. After tunnel drilling, the settlement data of ground surface were picked up. After tunnel simulation, the effect of support lining was investigated on the ground settlement. For this purpose, after each step of tunnel drilling, lining support with diameter of $35 \mathrm{~cm}$ was performed. The results show that:

- When aqueduct was situated perpendicular above the tunnel, the maximum ground settlement was occurred. This was critical configuration.

- When aqueduct was situated $4.5 \mathrm{~m}$ at the right side of the tunnel, the minimum ground settlement was occurred. This was safe configuration.

- In the first stage of drilling of four models, the ground settlement curve was aximetric because the aqueduct has not any effect of the ground settlement. In this condition, only tunneling lead to ground settlement.

- During the second stage of drilling till seventh stages of drilling, the ground settlement curve was un-aximetric because the aqueduct has important effect on the ground settlement. In this condition, tunneling lead to ground settlement too.

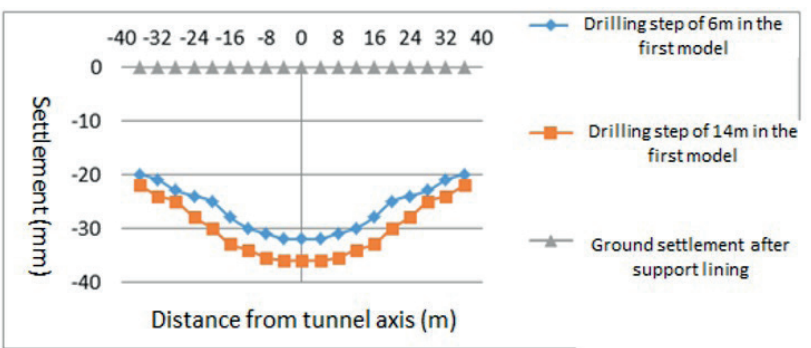

Fig. 18 diagram of settlement before and after the support lining for the firth model 
- In drilling stages of 6 and 14 the settlement was maximum, i.e., $32 \mathrm{~mm}$ and $36 \mathrm{~mm}$ respectively, because tunnel intersects with aqueduct. The settlement was decreased by increasing the distance from aqueduct.

- During the seventh stages of drilling to tenth stages of drilling, the ground settlement curve was aximetric because the aqueduct has not any effect on the ground settlement. In this condition, only tunneling leads to ground settlement.

\section{References}

[1] Terzaghi, K. "Applied Sedimentation", In: Trask, P. D. (ed.) Geologic Aspects of Soft-Ground Tunnelling, John Wiley and Sons, Inc., New York, NY, USA, 1950, pp. 193-209.

[2] Lee, K. M., Rowe, R. K., Lo, K. Y. "Subsidence owing to tunnelling. I. Estimating the gap parameter", Canadian Geotechnical Journal, 29(6), pp. 929-940, 1992.

https://doi.org/10.1139/t92-104

[3] Loganathan, N., Poulos, H. G. "Analytical Prediction for TunnelingInduced Ground Movements in Clays", Journal of Geotechnical and Geoenvironmental Engineering, 124(9), pp. 846-855, 1998. https://doi.org/10.1061/(ASCE)1090-0241(1998)124:9(846)

[4] Rowe, R. K., Lo, K. Y., Kack, G. J. "A method of estimating surface settlement above tunnels constructed in soft ground", Canadian Geotechnical Journal, 20(1), pp. 11-22, 1983. https://doi.org/10.1139/t83-002

[5] Gunn, M. J. "The prediction of surface settlement profiles due to tunneling", In: Predictive Soil Mechanics, Proceedings of the Wroth Memorial Symposium, St. Catherines College, Oxford, UK, 1993, pp. 55-67.

[6] Taylor, R. N. "Modelling of Tunnel Behaviour", Proceedings of the the Institution of Civil Engineers - Geotechnical Engineering, 131(3), pp. 127-132, 1998.

https://doi.org/10.1680/igeng.1998.30467

[7] Lambrughi, A., Rodriguez, L. M., Castellanza, R. "Development and validation of a 3D numerical model for TBM-EPB mechanised excavations", Computers and Geotechnics, 40, pp. 97-113, 2012.

https://doi.org/10.1016/j.compgeo.2011.10.004

[8] Vermeer, P. A., Bonnier, P. G., Möller, S. C. "On a smart use of 3D-FEM in tunneling", presented at The 8th International Symposium NUMOG VIII, Rome, Italy, April, 10-12, 2002.

[9] Martos, F. "Concerning an approximate equation of the subsidence trough and its time factors", In: International Strata Control Congress, Leipzig, Germany, 1958, pp. 191-205.

[10] Neaupane, K. M., Adhikari, N. R. "Prediction of tunneling-induced ground movement with the multi-layer perceptron", Tunnelling and Underground Space Technology, 21(2), pp. 151-159, 2006. https://doi.org/10.1016/j.tust.2005.07.001

[11] Peck, R. B. "Deep Excavations and Tunneling in Soft Ground", In: Proceedings of the 7th International Conference on Soil Mechanics and Foundation Engineering, Mexico City, Mexico, 1969, pp. 225-290.

[12] Schmidt, B. "Settlements and Ground Movements associated with tunneling in soil", PhD Thesis, University of Illinois, 1969.
- The settlement was zero when the lining support was installed. This behavior occurred in other aqueduct configuration.

- Bedding thickness and bedding layer angle have important effect on the ground settlement. The authors will study this important in a new future.

[13] Mair, R. J., Taylor, R. N. "Theme lecture: Bored tunnelling in the urban environment", In: Proceedings of the 14th International Conference on Soil Mechanics and Foundation Engineering, Hamburg, Germany, 1997, pp. 2353-2385.

[14] Cording, E. J., Hansmire, W. H. "Displacement around soft ground tunnels, General Report: Session IV, Tunnels in soil", In: Proceedings of the 5th Panamerican Conference on Soil Mechanics and Foundation Engineering, Buenos Aires, Argentina, 1975, pp. 87-95.

[15] Attewell, P. B., Woodman, J. P. "Predicting the dynamics of ground settlement and its derivatives by tunnelling in soil", Ground Engineering, 15(8), pp. 13-22, 1982.

[16] New, B. M., O'Reilly, M. P. "Tunnelling induced ground movements; predicting their magnitude and effects", In: Fourth International Conference on Ground Movements and Structures, Cardiff, UK, 1991, pp. 671-697.

[17] Mair, R. J., Taylor, R. N. "Theme lecture: Bored tunnelling in the urban environment", In: Proceedings of the 14th International Conference on Soil Mechanics and Foundation Engineering, Hamburg, Germany, 1997, pp. 2353-2385.

[18] Clough, G. W., Schmidt, B. "Design and performance of excavations and tunnels in soft clay. State of the Art report", In: International Symposium on Soft Clay, Bangkok, Thailand, 1977, pp. 980-1032.

[19] Xia, Y., Shi, Y., Lin, L., Zhang, Y., Tan, Q., Yang, Y. "Experimental Evaluation of Fragments from TBM Disc Cutting under Different Load Cases", Periodica Polytechnica Civil Engineering, 62(3), pp. 746-756, 2018. https://doi.org/10.3311/PPci.11961

[20] Haeri, H., Sarfarazi, V., Hedayat, A. "Suggesting a new testing device for determination of tensile strength of concrete", Structural Engineering and Mechanics, 60(6), pp. 939-952, 2016. https://doi.org/10.12989/sem.2016.60.6.939

[21] Haeri, H., Sarfarazi, V. Lazemi, H. "Experimental study of shear behavior of planar nonpersistent joint", Computer and Concrete, 17(5), pp. 639-653, 2016. https://doi.org/0.12989/cac.2016.17.5.639

[22] Wang, T., Dai, J.-G., Zheng, J.-J. "Multi-angle truss model for predicting the shear deformation of RC beams with low span-effective depth ratios", Engineering Structures, 91, pp. 85-95, 2015. https://doi.org/10.1016/j.engstruct.2015.02.035

[23] Wang, X., Zhu, Z., Wang, M., Ying, P., Zhou, L., Dong, Y. "Study of rock dynamic fracture toughness by using VB-SCSC specimens under medium-low speed impacts", Engineering Fracture Mechanics, 181, pp. 52-64, 2017. https://doi.org/10.1016/j.engfracmech.2017.06.024 
[24] Narimani, S., Chakeri, H., Davarpanah, S. M. "Simple and NonLinear Regression Techniques Used in Sandy-Clayey Soils to Predict the Pressuremeter Modulus and Limit Pressure: A Case Study of Tabriz Subway", Periodica Polytechnica Civil Engineering, 62(3), pp. 825-839, 2018. https://doi.org/10.3311/PPci.12063

[25] Qiao, S., Xia, J., Xia, Y., Liu, Z., Liu, J., Wang, A. "Establishment of Coal-rock Constitutive Models for Numerical Simulation of Coal-rock Cutting by Conical Picks", Periodica Polytechnica Civil Engineering, 63(2), pp. 456-464, 2019.

https://doi.org/10.3311/PPci.13084

[26] Sarfarazi, V., Haeri, H., Shemirani, A. B. "Direct and indirect methods for determination of mode I fracture toughness using PFC2D", Computers and Concrete, 20(1), pp. 39-47, 2017. https://doi.org/10.12989/cac.2017.20.1.039

[27] Sarfarazi, V., Faridi, H. R., Haeri H., Schubert, W. "A new approach for measurement of anisotropic tensile strength of concrete", Advances in Concrete Construction, 3(4), pp. 269-284, 2015. https://doi.org/10.12989/acc.2015.3.4.269

[28] Akbas, S. D. "Analytical solutions for static bending of edge cracked micro beams", Structural Engineering and Mechanics, 59(3), pp. 579-599, 2016. https://doi.org/10.12989/sem.2016.59.3.579

[29] Alipour, A., Mokharian, M., Chehreghani, S. "An Application of Fuzzy Sets to the Blastability Index (BI) Used in Rock Engineering", Periodica Polytechnica Civil Engineering, 62(3), pp. 580-589, 2018. https://doi.org/10.3311/PPci.11276

[30] Mohammad, A. "Statistical flexural toughness modeling of ultra-high performance mortar using response surface method", Computers and Concrete, 17(4), pp. 477-488, 2016. https://doi.org/10.12989/cac.2016.17.4.477

[31] Ahmadi, M. H., Molladavoodi, H. "A micromechanical SlidingDamage Model under Dynamic Compressive Loading", Periodica Polytechnica Civil Engineering, 63(1), pp. 168-183, 2019. https://doi.org/10.3311/PPci.13249

[32] Oetomo, J. J., Vincens, E., Dedecker, F., Morel, J.-C. "Modeling the $2 \mathrm{D}$ behavior of dry-stone retaining walls by a fully discrete element method", International Journal for Numerical and Analytical Methods in Geomechanics, 40(7), pp. 1099-1120, 2016. https://doi.org/10.1002/nag.2480

[33] Silling, S. A. "Stability of peridynamic correspondence material models and their particle discretizations", Computer Methods in Applied Mechanics and Engineering, 322, pp. 42-57, 2017. https://doi.org/10.1016/j.cma.2017.03.043

[34] Uzun Yaylacı, E., Yaylacı, M., Ölmez, H., Birinci, A. "Artificial neural network calculations for a receding contact problem", Computers and Concrete, 25(6), pp. 551-563, 2020. https://doi.org/10.12989/cac.2020.25.6.551
[35] Yaylacı, M., Eyüboğlu, A., Adıyaman, G., Uzun Yaylacı, E., Öner, E., Birinci, A. "Assessment of different solution methods for receding contact problems in functionally graded layered mediums", Mechanics of Materials, 154, Article number: 103730, 2021. https://doi.org/10.1016/j.mechmat.2020.103730

[36] Yaylacı, M., Yaylı, M., Uzun Yaylac1, E., Ölmez, H., Birinci, A. "Analyzing the contact problem of a functionally graded layer resting on an elastic half plane with theory of elasticity, finite element method and multilayer perceptron", Structural Engineering and Mechanics, 78(5), pp. 585-597, 2021. https://doi.org/10.12989/sem.2021.78.5.585

[37] Yaylaci, M. "The investigation crack problem through numerical analysis", Structural Engineering and Mechanics, 57(6), pp. 11431156, 2016. https://doi.org/10.12989/sem.2016.57.6.1143

[38] Yaylac1, M., Adıyaman, E., Öner, E., Birinci, A. "Investigation of continuous and discontinuous contact cases in the contact mechanics of graded materials using analytical method and FEM", Computers and Concrete, 27(3), pp. 199-210, 2021.

https://doi.org/10.12989/cac.2021.27.3.199

[39] Yaylacı, M., Adıyaman, G., Öner, E., Birinci, A. "Examination of analytical and finite element solutions regarding contact of a functionally graded layer", Structural Engineering and Mechanics, 76(3), pp. 325-336, 2020. https://doi.org/10.12989/sem.2020.76.3.325

[40] Yaylaci, M., Birinci, A. "The receding contact problem of two elastic layers supported by two elastic quarter planes", Structural Engineering and Mechanics, 48(2), pp. 241-255, 2013. https://doi.org/10.12989/sem.2013.48.2.241

[41] Öner, E., Yaylaci, M., Birinci, A. "Analytical solution of a contact problem and comparison with the results from FEM", Structural Engineering And Mechanics, 54(4), pp. 607-622, 2015. https://doi.org/10.12989/sem.2015.54.4.607

[42] Adiyaman, G., Yaylac1, M., Birinci, A. "Analytical and finite element solution of a receding contact problem", Structural Engineering and Mechanics, 54(1), pp. 69-85, 2015. https://doi.org/10.12989/sem.2015.54.1.069

[43] Cundall, P. A. "Computer Simulations of Dense Sphere Assemblies", Studies in Applied Mechanics, 20, pp. 113-123, 1988. https://doi.org/10.1016/B978-0-444-70523-5.50021-7

[44] ITASCA "PFC2D/3D (Particle Flow Code in 2/3 Dimensions) User's Guides", Itasca Consulting Group Inc., Minneapolis, MN, USA, 2004/2005. 